\title{
Correction to: Vogesella perlucida-induced bacteremia in an advanced-age patient: first case report
}

Zengxian $\mathrm{Yu}^{1+}{ }^{1}$, Fang Zhu ${ }^{3+}$, Xinghe Tao ${ }^{1}$, Lu Zhang ${ }^{1}$, Suliu Wu ${ }^{2}$, Chunfu Dong ${ }^{1}$, Yeqing Dong ${ }^{1}$, Ge Chen ${ }^{2}$, Xinyang Zhou ${ }^{2}$, Yinfei Fang ${ }^{3}$ and Kechen $\mathrm{Xu}^{1^{*}}$

\section{Correction to: BMC Infect Dis 20, 687 (2020) https://doi.org/10.1186/s12879-020-05420-w}

Following publication of the original article [1], the authors identified errors in some authors' affiliations.

Below the correct affiliations are given:

- Fang Zhu's affiliation should be Pathology department, Jinhua Central Hospital, Jinhua 321000, Zhejiang, China;

- Suliu Wu's affiliation should be Wuyi First People's Hospital, Wuyi, Jinhua 321200, Zhejiang, China;

-Ge Chen's affiliation should be Wuyi First People's Hospital, Wuyi, Jinhua 321200, Zhejiang, China;

- Xinyang Zhou's affiliation should be Wuyi First People's Hospital, Wuyi, Jinhua 321200, Zhejiang, China;

- Yinfei Fang's affiliation should be Pathology department, Jinhua Central Hospital, Jinhua 321000, Zhejiang, China.

The author group has been updated above.

\section{Author details}

${ }^{1}$ Clinical Laboratory Center, Wuyi First People's Hospital, Wuyi, Jinhua, Zhejiang 321200, China. ${ }^{2}$ Wuyi First People's Hospital, Wuyi, Jinhua, Zhejiang

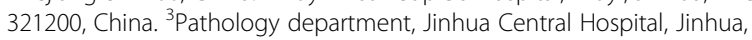
Zhejiang 321000, China.
Published online: 29 September 2020

\section{Reference}

1. $Y u Z$, et al. Vogesella perlucida-induced bacteremia in an advanced-age patient: first case report. BMC Infect Dis. 2020;20:687 https://doi.org/10.1186/ s12879-020-05420-w.

* Correspondence: 8015059@zju.edu.cn

${ }^{\dagger}$ Zengxian Yu and Fang Zhu contributed equally to this work.

${ }^{1}$ Clinical Laboratory Center, Wuyi First People's Hospital, Wuyi, Jinhua,

Zhejiang 321200, China

Full list of author information is available at the end of the article

C C The Author(s). 2020 Open Access This article is licensed under a Creative Commons Attribution 4.0 International License, which permits use, sharing, adaptation, distribution and reproduction in any medium or format, as long as you give appropriate credit to the original author(s) and the source, provide a link to the Creative Commons licence, and indicate if changes were made. The images or other third party material in this article are included in the article's Creative Commons licence, unless indicated otherwise in a credit line to the material. If material is not included in the article's Creative Commons licence and your intended use is not permitted by statutory regulation or exceeds the permitted use, you will need to obtain permission directly from the copyright holder. To view a copy of this licence, visit http://creativecommons.org/licenses/by/4.0/ The Creative Commons Public Domain Dedication waiver (http://creativecommons.org/publicdomain/zero/1.0/) applies to the data made available in this article, unless otherwise stated in a credit line to the data. 